\title{
Decomposition of Malaysian Production Structure Input-Output Approach
}

\author{
HUSSAIN ALI BEKHET \\ Finance and Economics Department \\ College of Business Management and Accounting \\ University Tenaga Nasional (UNITEN) \\ Muadzam Shah Campus, Pahang, Malaysia \\ Tel: (609) 4552020 ext. 2049 \\ E-mail: profhussain@uniten.edu.my,drhussain175@hotmail.com
}

\begin{abstract}
Structural decomposition techniques are widely used to break down the growth in some variable into the changes in its determinants. Over the past two decades, input-output structural decomposition analysis (SDA) has developed into a major analytical tool. We review the development of SDA and its relationship to other methodologies. We present the fundamental principle of alternative approaches to deriving SDA estimating similarities and explore the various \& decompositions of changes in I-0 tables. Using I-O Tables for the Malaysian Economy 1983-2000, this comparative study focuses on changes in the economic structure with different levels of development over time (1983-2000). The change in the economic structure is decomposed into two initial components (Technology and total output). According to the results, there are similarities over time in the national structure of production patterns of intermediate use of commodities. Also, the results indicate a rather remarkable degree of commonality in the patterns of growth processes, with more significant differences between sectors than between tables. However, the most changes within sectors, and the Malaysian table as a whole, seem to result from changes in $\underline{x}$, and $\underline{f}$. $\underline{A}$ seems to have remained relatively unchanged.
\end{abstract}

Keywords: Input-Output Model, Economic Structure, Structural Change, Coefficient Change, Comparative Statics, Production Techniques

\section{Introduction:}

This paper attempts an historical comparison of the economic production structure of the Malaysian economy using input-output relationships. The pioneering study in this field was by CHENERY and WATANABE [1958], which indicated that the national production structures of such developed countries (DCs) as Japan, Italy, Norway, and United States are similar. SANTHANAM and PATIL [1972] have shown that the production structure of India, a less developed country (LDC), also resembles those of the above developed countries. These studies are based on the analysis of the production structure of only a limited number of countries, however, and, as has been suggested in earlier studies, further investigation is required.

Comparisons of the production structures of different economies have largely focused on international comparisons (LENOITEF, (1963); SIMPSON, and TSUKUI, (1965); and HELMSTADTER, 1969), but with the development in recent years of several survey-type input-output models it is possible to extend this type of analysis to comparisons of regional production structures. Such regional comparisons are appealing in that little work has been done in this area and, in contrast with international comparisons, variations in accounting conventions and relative prices should be small.

A path-breaking analysis of input-output tables of different countries was undertaken by CHAENERY and WATANABE (1958). They conclude that a general similarity in the relationships among productive sectors in industrialized countries exists, although there are substantial differences in individual input-output coefficients. The production structure was analyzed by grouping industries according to patterns of output distribution and input sources. Industries were categorized numerically according to the proportions of output sold to other industries and to final demand, and also by the proportions of inputs purchased from other industries and utilized directly. In this manner interdependence was examined from both the demand and the supply sides.

Although a large part of the analysis was approached on a coefficient-by-coefficient basis, one purpose of the study was to establish a hierarchy of sectors leading from finished to primary products and then to determine the extent to which the resulting sequence was similar in each nation 
In this paper I extend the existing comparisons and consider the production structure of Malaysia in its historical perspective. The input-output tables considered for the purposes of national comparison are for 1983, 1987, 1991 and 2000.

The purpose of this paper is to find out whether the structure of production of Malaysia is in any way comparable over time, between different tables. That is, whether there has been significant change in the technical coefficients over time. The decomposition methods used BEKHET (2009) indicated that there are some changes. In this paper other techniques of decomposition will be discussed and utilized.

The rest of this paper is in five sections. Section Two considers the literature review of the structural decomposition analysis. Section Three discuss the methodology of the structural decomposition analysis. This would be including the comparability of production techniques, the comparability of intermediate use, and the overall comparison of intermediate use. Section Four examines the results analysis. Section Five presents some policy implications. Section Six offers some conclusion and remarks.

The following notation is used in this paper:

$\mathrm{a}_{\mathrm{ij} 0}$ is the input coefficient for the base year.

$\mathrm{a}_{\mathrm{ij} 1}$ is the input coefficient for the comparator year.

$\mathrm{x}_{\mathrm{j} 0}$ is total output for the base year.

$\mathrm{x}_{\mathrm{j} 1}$ is total output for the comparator year.

\section{Literature Review of the Structural Decomposition Analysis:}

The antecedents of structural decomposition analysis are the various analyses of changes in US input-output tables as performed by LEONTIEF $(1941,1953)$. More formal dynamic analyses in this vein, focusing on investment and technological change, were performed by CARTER, culminating in her 1970 volume (CARTER, 1970). A broader approach that used features of input-output analyses along with more general macroeconomics was developed for the examination of economic development by CHENERY et al. (1962) and CHENERY and SYRQUIN (1975).

The first formal identify-splitting derivation known to us is the three-part decomposition of sources of change in air pollution emissions as performed by LEONTIEF and FORD (1972). SKOLKA's work on structural decomposition analysis began in the mid-1970s (see, for example, SKOLKA, 1977) and culminated in the expanded set of estimating equations in his classic paper (SKOLKA, 1989), which is perhaps the most cited work in the field. However, the SKOLKA estimating equations were not formally derived, so certain desirable properties are not ensured. The most extensive derivation to date is the 14 estimating equations, comparable analytically with that of a neoclassical, two-tier KLEM (capital, labour, energy and materials) production function, by ROSE and CHEN (1991a). This was also the first paper to attempt to address the properties of the structural decomposition analysis production function and to compare them with neoclassical formulations.

Structural decomposition analysis has become a popular methodology for several reasons. First, it overcomes many of the static features of input-output models and is able to examine changes over time in technical coefficients and sectoral mix. Thus far, it has only been used for historical analysis, but some recent work indicates how it might be used as a forecasting tool (see, for example, CASLER et al., 1991; ROSE \& CHEN, 1991b). In a similar vein, structural decomposition analysis enables the analyst to examine responses to price changes, which are only implicit in even value-based input-output tables. As such, it may involve an as yet undiscovered duality feature.

Another reason for the increasingly widespread use of structural decomposition analysis is that it is a pragmatic alternative to econometric estimation. Analysis of similar topics using econometrics requires a time series covering 15 years or more, and not only for output and primary factors of production but all intermediate inputs as well. In contrast, structural decomposition analysis requires only two input-output tables: one for the base year and one for the comparator year of the analysis. Moreover, it has been demonstrated heuristically at least that the structural decomposition analysis estimating equations are insignificantly more restrictive than the most advanced of the economically estimated production functions-flexible functional forms, such as the translog.

Still another asset of structural decomposition analysis arises from its input-output base-the comprehensive accounting of all inputs in production. As environmental and natural resource issues became more prominent, there was a greater need to look at root causes of pollution and depletion. These are more readily linked to intermediate sectors, which are omitted in the more standard approaches (ROSE and CASLER, 1996).

Beyond that, structural decomposition analysis has seen a broad set of applications. These include examining sources of change in international trade (for example, KANEMITSU \& OHNISHI, 1989; CHEN \& WU, 1995), technological change (for example, STERNER, 1985; OoSTERHAVEN \& VAN DER LINDEN, 1994), energy use (for example, LIN \& POLENSKE, 1995), workforce requirements (for example, WOLFF, 1985; HAN, 1995), services (for example, 
BARKER, 1990) and development planning (for example, SIEGE1 et al., 1996). These empirical studies have yielded valuable findings about the success of energy conservation measures; limitations of import substitution; prevalence of changing tastes; pervasiveness of factor productivity; and importance of skill attainment.

\section{The Data and Methodology:}

Basically, the present study uses secondary data based on the four input-output tables compiled for the Malaysia economy so far. These tables were produced by the Department of Statistics. For analytical and comparable purposes, the original input-output tables consisting of different number of sectors are aggregated into 39 sectors based on International Standard Industrial Classification (ISIC). These sectors are shown in (Table 1). I proposed the following decomposition for the analysis of the influence on input coefficient and output levels of changes in the technology for the two time periods 0 for base table and 1 for comparator table.

\subsection{Comparability of Production Techniques}

When comparing the overall structure of Malaysian production in 1983 with that of the other input-output tables available for the Malaysian economy, it would be fruitful to make a detailed comparison of the production techniques of the sectors of the Malaysian input-output table of 1983 with those of 1987, 1991 and 2000. In inter-industry analysis, the technique of production of a sector is indicated by the input coefficient in the relevant column vector of the input coefficient matrix. In what follows, I will use the techniques of production of the sectors for the Malaysia, as given by the input coefficient matrices. There are two methods of measuring the comparability of production techniques, industry by industry. These two methods are dealt with in the next two subsections.

\subsubsection{Absolute Column Measure}

The first measure of the comparability of production techniques on an industry by industry basis is derived from the sum of absolute differences in coefficients ("absolute column measure ") divided by an "average column total" for two years, PTj. The former is the ratio of the sum of absolute differences of all the coefficients of the jth column vector of these tables, divided by the arithmetic mean of all the coefficients of the two tables. The latter is the median value of the former. This measure can be expressed mathematically, by:

$$
\mathrm{PT}_{j}=\frac{\sum_{\mathrm{i}=1}^{\mathrm{n}}\left|\mathrm{a}_{\mathrm{ij} 0}-\mathrm{a}_{\mathrm{ij} 1}\right|}{(1 / 2) \sum_{\mathrm{i}=1}^{\mathrm{n}}\left(\mathrm{a}_{\mathrm{ij} 0}+\mathrm{a}_{\mathrm{ij} 1}\right)}
$$

In matrix notation this is:

$$
\mathrm{PT}_{j}=\frac{\underline{\mathrm{i}}^{\prime}\left|\underline{\mathrm{A}}_{0}-\underline{\mathrm{A}}\right|}{(1 / 2) \underline{\mathrm{i}}^{\prime}\left(\underline{\mathrm{A}}_{0}-\underline{\mathrm{A}}^{\prime}\right)}
$$

Here the $a_{\mathrm{ij} 0}$ is the base year input coefficient, and $\mathrm{a}_{\mathrm{ij} 1}$ is the input coefficients for the comparator year. From the definition above, it is clear that the value of $\mathrm{PT}_{\mathrm{j}}$ is in the range $(0,2)$. Thus a value of zero for $\mathrm{PT}_{\mathrm{j}}$ indicates a maximum level of measurable similarity between production techniques, while a value of two indicates the maximum level of measurable difference. If $\mathrm{PT}_{\mathrm{j}}$ is zero, the production techniques will be identical.

In their study, CHENERY and WATANABE [1958] have accepted the value of $\mathrm{PT}_{\mathrm{j}}=0.80$ as the dividing line; whenever the value of $\mathrm{PT}_{\mathrm{j}}$ is less than or equal to 0.80 the production techniques employed in both table (base and comparator) are said to be comparable. I have computed the values of $\mathrm{PT}_{\mathrm{j}}$ for the 39 sectors between input-output table for 1983 and each of the other three tables of the Malaysian economy and between other successive tables. These results are presented in table 2 .

Insert Table 2 Here.

\subsubsection{Frequency Distribution Method}

Another useful method for comparing the production techniques of two tables would be a frequency distribution of the sectors by using the values of $\mathrm{PT}_{\mathrm{j}} \mathrm{s}$ as shown in Table 2 . We can use them in summary form to determine the extent to which the four tables are comparable. This has been done in Table 3, in which all the possible combination two-table comparisons have been classified by the magnitude of the column difference.

Insert Table 3 Here.

\subsection{Comparability in Intermediate Use:}

In the preceding section, we used the technique of comparing the input coefficients of the tables. Another useful approach to the problem is to examine the extent of overall similarities in the use of a given good as an intermediate product. Similarity between input-output tables for two years (base and comparator) in the intermediate use of commodity $\mathrm{i}$ by industry $\mathrm{j}$ can be analysed by comparing the intermediate use in the comparator table that would be necessary, using the input coefficients in the base table, with the actual level of use in the comparator table. This could 
be done for an industry $i$ by multiplying the production levels of the economy in the table of the comparator year with the input coefficients (along the row) of the base table year, and dividing this sum by the total intermediate use of industry $\mathrm{i}$ of comparator year, $\mathrm{IU}_{\mathrm{i}}$. This measure can be expressed mathematically as:

$$
I U_{i}=\frac{\sum_{j=1}^{n} a_{i j 0} X_{j 1}}{\sum_{j=1}^{n} a_{i j 1} X_{j 1}}
$$

In matrix notation this is:

$$
\mathrm{IU} \mathrm{U}_{\mathrm{i}}=\frac{\underline{\mathrm{i}}^{\prime} \underline{\mathrm{A}}_{0} \underline{\mathrm{x}}_{1}}{\underline{\mathrm{i}}^{\prime} \underline{\mathrm{A}}_{1}}
$$

Here $\underline{i}$ is the unit vector. From the definition above, it is clear that the value of $\mathrm{IU}_{\mathrm{i}}$ is in the range $(0, \infty)$. If the value of $\mathrm{IU}_{\mathrm{i}}$ is close to one, the similarity of the technical production between the two input-output tables will be large. On the other hand, if this value deviates from unity, the production techniques will be different.

Deviation of the value of $\mathrm{IU}_{\mathrm{i}}$ from unity may be due to various factors, such as input substitution without compensating price variations, or conceptual differences in the definition of the products or sectors. The values of $\mathrm{IU}_{\mathrm{i}}$ are affected by the patterns of intermediate use in the base year. This value is computed for each pair of input-output tables for the Malaysian economy by using Equation (3). These results are shown in table 4.

\section{Insert Table 4 Here.}

\subsection{Overall Comparison}

So far, our interindustry comparisons have been made in terms of columns and rows, and have been made on individual sectors separately. An equally interesting aspect of the study of input-output table comparison is the comparison of the interindustry tables as a whole for a given pair of tables. Such an overall comparison could be made in terms of the weighted average of row ratios or columns ratios, where the weights are the output levels for sectors of the table accepted as the base for comparison. The similarity of the overall pattern of the intermediate use for the input-output table as a whole can be measured by extending either the column or row comparisons. It should be noted that the weighted average of the column or row ratio leads to the same final result, the weighted average of our earlier ratio of $\mathrm{IU}_{\mathrm{i}}$. The weighted average ratio of $\mathrm{IU}_{\mathrm{i}}$ may be expressed as follows:

$$
\mathrm{IU}_{\mathrm{i}}=\frac{\sum_{\mathrm{i}=1}^{\mathrm{n}} \sum_{\mathrm{j}=1}^{\mathrm{n}} \mathrm{a}_{\mathrm{ij} 0} \mathrm{X}_{\mathrm{j} 1}}{\sum_{\mathrm{i}=1}^{\mathrm{n}} \sum_{\mathrm{j}=1}^{\mathrm{n}} \mathrm{a}_{\mathrm{i} 1} \mathrm{X} \mathrm{X}_{\mathrm{j} 1}}
$$

We can write this in matrix form as:

$$
\mathrm{IU} \mathrm{U}_{\mathrm{i}}=\frac{\underline{\mathrm{i}}^{\prime} \underline{\mathrm{A}}_{\mathrm{A}} \underline{\mathrm{x}}_{1}}{\underline{\mathrm{i}}^{\prime} \underline{\mathrm{A}}_{1} \underline{\mathrm{x}}_{1}}
$$

Here, $x_{j 1}$ is the total output for the comparator year. Equation (5) has been applied for the Malaysian economy of the period under study. These results are shown in table 5 .

Insert Table 5 Here.

Since the input-output table chosen as the base affects the ratio of overall comparison, it would be of interest to reduce the impact of any table as the base table by accepting a mixed base. The ratio of overall comparison with a mixed base of different output level, OC, may be expressed as follows:

$$
O C=\left[\frac{\sum_{i=1}^{n} \sum_{j=1}^{n} a_{i j_{0}} x_{j_{1}} \sum_{i=1}^{n} \sum_{j=1}^{n} a_{i j_{0}} x_{j_{0}}}{\sum_{i=1}^{n} \sum_{j=1}^{n} a_{i j_{1}} x_{j_{1}} \sum_{i=1}^{n} \sum_{j=1}^{n} a_{i j_{1}} x_{j_{0}}}\right]^{\frac{1}{2}}
$$

And in matrix notation:

$$
\mathrm{OC}=\left\{\begin{array}{ll}
\underline{i}^{\prime} \underline{\mathrm{A}}_{0} \underline{\mathrm{x}}_{1} & \underline{\mathrm{i}}^{\prime} \underline{\mathrm{A}}_{0} \underline{\mathrm{x}}_{0} \\
\underline{\mathrm{i}}^{\prime} \underline{\mathrm{A}}_{1} \underline{\mathrm{x}}_{1} & \underline{\mathrm{i}}^{\prime} \underline{\mathrm{A}}_{1} \underline{\mathrm{x}}_{0}
\end{array}\right\}^{\frac{1}{2}}
$$


Where, $\mathrm{x}_{\mathrm{j} 0}$ is total output of the base year. I have used Equation (7) for the Malaysian economy for the period 1983-2000. These values of OC are presented in Table 6.

Insert Table 6 Here.

\section{Analysis of the Results:}

In this section, interpretation will be made of the application of the techniques introduced in Section 3 above to the input-output data for the economy of Malaysia. The period of the analysis is from 1983 to 2000.

Table 2 shows the comparison between four input-output tables available for the period mentioned above. $\mathrm{The}_{\mathrm{PT}}$ values have been computed and compared for 39 sectors, ie., as shown in Table 2, between all combinations of the tables. The results indicate that the Malaysian production techniques in 1983 are reasonably similar to those in 2000, and if we take the production techniques in 1987 again are reasonably similar to those in 2000 . The production techniques are shown to be quite similar in Oils \& Fats product, Wooden Products, Paper \& Printing products, China, Glass, Cement \& Other Non-met Mineral products, Building \& Construction, Hotel \& Restaurants, and Other Services sectors. If we take the Mean of $\mathrm{PT}_{\mathrm{j}}$, then the production techniques are shown to be quite similar in the case of Livestock Breeding, Foods Production other, Wearing Apparel, Paints, Lacquers \& Other Chemical product, Petroleum \& Coal product, Plastic products, Non-Electricity \& Electricity Machinery, Transport, Banks, Finance \& Insurance, and Health sectors. The maximum level of differences is in the case of Forestry \& Logging product, Fishing, Industrial Chemicals, Other Transport Equipment, Electricity \& Gas, and Communication sectors. This means the $\mathrm{PT}_{\mathrm{j}}$ are greater than or closer to unity for these sectors.

However, the most similar for all combinations among input-output tables is the 1983-1987, 1983-1991 and 1987-1991 cases, where the majority of the value of $\mathrm{PT}_{\mathrm{j}}$ is less than unity and in some cases closer to zero. Therefore, most industries show little if any change where comparability of production techniques is measured by absolute column change (See Table 3).

Following CHENERY and WATANABE [1958], if we take the value 0.8 of $\mathrm{PT}_{\mathrm{j}}$ for judging whether the production techniques of two tables are similar, then there are only two pairs of tables which would be regarded as similar. These combinations are 1983-1987 and 1987-1991. However, this may be because these combinations of the tables were very close in time. But if the value of $\mathrm{PT}_{\mathrm{j}}$ of one is accepted as the guiding indicator rather than 0.8 , the tables for 1983-1991, 1987-1991, and 1991-2000 are the least comparable, since 37, 35 and 35 sectors, respectively, show values below unity, whereas in the case of 1983-1987, 1983-2000 and 1987-2000 the number of sectors is 34, 34 and 31 respectively (see Table 3).

For developing countries, the production techniques are similar in most of the Manufacturing Industries and are least comparable in the non-Manufacturing Industries [Al-SAID, 1985; p.158]. Following SANTHANUMA and PATIL [1972], if we take a $\mathrm{PT}_{\mathrm{j}}$ value of 1 or less to indicate similarity, we see that the production techniques for the 1983-1991 periods are very similar. However, the $\mathrm{PT}_{\mathrm{j}}$ value of the Fishing and Electricity \& Gas sectors are slightly higher than one. This is because these sectors are producing almost finished materials which are, in fact, semi-finished and their outputs go directly to final demand.

It may be noted from Table 4 that the values of $\mathrm{IU}_{\mathrm{i}}$ for the Malaysian economy show that the patterns of intermediate use in the various sectors is similar and close to unity only about 67\%,69\% of sectors for 1983-1987 and 1987-1991 respectively. We coded these sectors with mark * (see Table 4). Howsoever, the most comparable pairs of years are 1983-1987 and 1987-1991, and the least comparable pair is 1991-2000 and 1983-2000. The reason for this may be that the structure of the Malaysian economy changed radically after the economic plans for the period 1980-1990. If we consider the (0.8-1.2) value as critical range of judgment then the most similarity of technical production between 1983-1987 and 1987-1991 were very large. This may be because these three tables were very close in time. Also interesting is the fact that the historical comparisons indicate an increasing constancy over time in intermediate use patterns in the following sectors; Agriculture products, Rubber Primary products, Fishing, Beverages \& Tobacco product, basic Metal \& Other Metal product, Non-Electricity and Electricity Machinery, Wholesale \& Retail Trade, Real estate \& Ownership dwellings, Education and Health. Beyond that, there was decreasing constancy over time in intermediate use in Foods Production, Oils \& Fats product, Textile products, Wearing Apparel, Furniture \& Fixtures, Industrial Chemicals, Paints, Lacquers \& Other Chemical product, Petroleum \& Coal product, processed Rubber \& Rubber product, Electricity \& Gas, Hotel \& Restaurants sectors. There are some indications that changes in intermediate relations have been associated with policies adopted during the period. The increase in intermediate use and the variation in its composition during the process of development are the result of change in the composition of demand and in technology.

Now, if we consider the input-output table comparison as a whole for any given pair of tables, we get two values of $\mathrm{IU}_{\mathrm{i}}$ by altering the base. It may be noted from Table 5 that the overall comparison of all possible combination of pairs tables 
of Malaysian economy indicates that 1983-1991, 1987-1991, 1987-2000, 2000-1983, 2000-1987, and 2000-1991 are the most comparable.

Also, if we consider the ratio of overall comparison with a mixed base of different output level, it found that 1983-198, 1983-1991 and 1987-1991 are most similar of tables (see Table 6). However, the results indicate that the most differences of all combinations of tables are 1983-2000, 1987-2000 and 1991-2000. Moreover, the similarity for the Malaysian economy has decreased over the period 1983-2000, reflecting the changes that have taken place in the economy.

\section{Policy Implications:}

The results shown in Tables 2 to 6, and discussed in the previous section, show how far the Malaysian policy has been successfully achieved.

We see that there are similarities over time in the national structure of production, patterns of intermediate use of commodities, and input coefficients between 1983-1987, and 1987-1991. It appears that the degree of continuity in the production structure is dependent to a great extent on differences in the level of development of each sectors [see Tables 2-6], and overall [see Section 4]. That is to say, the more constant the level of development of sectors of the Malaysian economy over time, shown by a comparison of the tables for any two years of the 1983-2000 period, the more similar is the production structure. Also, it shows that imports are increasing and exports of non-oil goods, decreasing over time [see www.epu.jpm.my/]. The results show that although some progress has been made, it falls far short of what the planners desired.

This result provides more evidence supporting the main finding of the studies of the structural analysis of the Malaysian economy by linkages of input-output tables (SHUJA, 2007), and the assessment of development and structural change (BEKHET, 2009).

It is important to recognize that part of the change in coefficients is due to substitution effects, resulting from changes in relative prices. Unfortunately, information on price structure by sector is not available for Malaysia. Also, the validity of these results needs to be tested further through studies covering a larger number of input-output tables for the Malaysian economy. However, the conclusions drawn from the preceding tables suggest that, except for the effects due to the new industries (new technology), there may be no significant change in the production technology during the coming five years unless a drastic change in the structure of production takes place.

It needs to be emphasised here that the level of accuracy of studies in national comparison depends primarily on comparability of national input- output tables. It should also be noted that there is considerable information loss with a high degree of aggregation [see for example FISHER, 1958; NEUDECKER, 1970; MORIMOTO, 1970; BLIN and COHEN, 1977; VAN DRIEL, 1980; and BULMER-THOMAS, 1982]. There is greater likelihood that results would be more meaningful with a higher level of disaggregation in national input-output tables.

\section{Conclusions:}

In this paper I have discussed some methods to measure the structure of production of the Malaysian economy. These methods are the comparability of production techniques, comparability of intermediate use, comparability of the overall comparison of intermediate use.

According to the results, there are similarities over time in the national structure of production patterns of intermediate use of commodities.

This and the previous two papers have discussed change in $\underline{x}, \underline{\mathrm{f}}, \underline{\mathrm{A}}$, and $(\underline{\mathrm{I}}-\underline{\mathrm{A}})^{-1}$. As discussed in this and the previous two papers most changes within sectors, and the Malaysian table as a whole, seem to result from changes in $\underline{x}$, and $\underline{\mathrm{f}} . \underline{\mathrm{A}}$ seems to have remained relatively unchanged.

\section{References}

AL- SAID, S.A. (1985). Comparison of the Input-Output Techniques and the Stage of Development, unpublished Ph.D thesis, The University of Wales, Aberystwyth, UK.

BAER, W., FONSECA, M.A.R. \& GUILHOTO, J.J.M. (1987). Structural changes in Brazil's industrial economy, 1960- 80, World Development, 14, pp.275-286.

BARKER, T. (1990). Sources of structured change for the UK service industries, 1979-84, Economic Systems Research, 2, pp.173-183.

BEKHET, H.A. (1992). The relation between development planning and macroeconomic policy models, Journal of Journal of Economic and Administration Science, Baghdad University, Vol.1, No.1.

BEKHET, H.A. (1998). Measuring the effect of final demand value for Iraqi Economy, 1976-1990, Journal of Economic and Administration Science, Baghdad University, Vol.5, No.14. 
BEKHET, H.A. (2000). The development of sectoral multipliers structure of the Iraqi Economy, 1978-1988, DIRASAT Journal, Administrative Science Division, Jordanian University, Vol.27, No.1.

BEKHET, H.A. (2009). Assessing Economic Connectedness Degree of the Malaysian Economy: Input-Output Model Approach, International Journal of Finance and Economics, Vol.1, No.2.

BEZDEK, R.H., \& WENDLING, R.M. (1976). Disaggregation of structural change in the American economy: 1947-1966, Review of Income and Wealth, 22, pp.167-185.

BLIN, J.M. and COHEN, C. (1977). "Technological similarity and aggregation in input-output system: a cluster analytic approach", Review of Economics and Statistics, Vol.60, pp.82-91.

BULMER-THOMAS, V. (1982). Input- output analysis in developing countries: sources, methods and applications. New York: Wiley.

CARTER, A.P. (1970). Structural Change in the American Economy, Harvard University Press, Cambridge, MA.

CASLER, S.; AFRIASABI, A. \& MCCAULEY, M. (1991). Decomposing change in energy input-output coefficients, Resources and Energy, 13, pp.95-109.

CAVES, D.W., CHRISTENSEN, L.R., and DIEWERT, W.E. (1982). The Economic theory of index numbers and the measurement of input, output, and productivity, Econometrica, 50, pp.1393-1414.

CHEN, C.Y. \& Wu, R.H. (1995). Effects of restructuring of international trade on changing energy use patterns and $\mathrm{CO}_{2}$ emissions in Taiwan: 1981-1991, Proceedings of the 18th IAEE International Conference, pp. 351-360.

CHENERY, H. \& SYRQUIN, M. (1975). Patterns of Development, 1950-1970, Oxford University Press, London.

CHENERY, H. \& SYRQUIN, M. (1979), A comparative analysis of industrial growth. In: R.C.O. CHENERY, H.B., \& Watanabe, T. (1958). "International comparisons of the structure of production", Econometrica, Vol.26, pp.487-521.

CHENERY, H., SHISHIDO, S. \& WATANABE, T. (1962). The pattern of Japanese growth, 1914-1954, Econometrica, 30, pp. 98-139.

DIETZENBACHER E. and LOS, B. (1998). Structural decomposition techniques: sense and sensitivity, Economic Systems Research, Vol.10, pp.307-2323.

EMERSON, J., \& RINGLEB, Al. (1977). A comparison of regional production structure, Papers in Regional Science, Vol.39, No.1, pp.85-98.

FELDMAN, S.J., McCLAIN, D. \& PALMER, K. (1987). Sources of structural change in the United States 1963- 1978: an input-output perspective, Review of Economics and Statistics, 69, pp. 503-510.

FISHER, W.H. (1958). "Criteria for aggregation in input-output analysis", Review of Economics and Statistics, Vol.40, pp.250-260.

FOSSELL, O. (1989). The input-output framework for analyzing the transmission of industrial progress between industries, Economic Systems Research, 1, PP.429-445.

FUJIKAWA, K.; IZUMI, H; and MILANA, C. (1995a). Multilateral Comparison of Cost Structure in the Input-Output Tables of Japan, the US and West Germany, Economic Systems Research, Vol.7, pp.321-42.

FUJIKAWA, K., IZUMI, H. and MILANA, C. (1995b). A Comparison of cost structures in Japan and the US using input-output tables, Journal of Applied Input-Output Analysis, 2, pp.1-23.

HAN, X. (1995). 7-65.

HEWINGS, G. J.D., DA FONSECA, M.A.R., GUILHOTO, J.J.M., \& SONIS, E.M. (1989). Key sectors and structural change in the Brazilian economy: a comparison of alternative approaches and their policy implications. Journal of Policy Modeling, Vol.11, No.1, pp.67-90.

KANEMITSU, H. \& OHNISHI, H. (1989). An input-output analysis of technological change in the Japanese economy: 1970-1980, in: R. MILLER et al. (eds), Frontiers of Input-Output Analysis, (New York, Oxford University Press).

KUBO, Y., \& Robinson, S. (1984). Sources of industrial growth and structural change: a comparative analysis of eight economies. In: Proceedings of the Seventh International Conference on Input-Output Techniques. New York: UNIDO, United Nations.

LAHER, M.L., and DIETZENBACHER, E. (2001). Input-Output Analysis: Frontiers and Extensions, (ed), Palgrave Macmillan.

LEONTIEF, W. \& FORD, D. (1972). Air pollution and economic structure, in: A. Brody \& A. Carter (eds) Contributions to Input-Output Analysis (Amsterdam, North-Holland). 
LEONTIEF, W. (1936). Quantitative Input-Output Relations in the Economic System of the United States, Review of Economics and Statistics, 18, pp.105-25.

LEONTIEF, W. (1941). Structure of the American economy (New York, Oxford University Press).

LEONTIEF, W. (1953). Studies in the structure of the American Economy (New York, Oxford University Press).

LIN, X. \& POLENSKE, K.R. (1995), Input-output anatomy of China's energy use changes in the 1980s, Economic Systems Research, 7, pp. 67-83.

MILANA, C. (2000). "The input-output structural decomposition analysis of flexible production systems", in Input-Output Analysis: Frontiers and Extensions, (Ed), M.L. LAHR, E. DIETZENBACHER, Macmillan, London.

MORIMOTO, Y. (1970). “On aggregation problems in input-output analysis", Review of Economic Studies, Vol.37, pp.119-126.

MORIMOTO, Y. (1971). “A note on weighted aggregation in input-output analysis”, International Economic Review, Vol.12, pp.138-142.

NEUDECKER, H. (1970). 'Aggregation in input-output analysis: an extension of Fisher's method”, Econometrica, Vol.38, pp.921-926.

OECD, (1995). The OECD Input-Output Database, Paris.

RICHARDSON, J.D. (1971). Constant-market-shares analysis of export growth. Journal of International Economics, 1, pp.227-239.

ROSE, A. \& CHEN, C.Y. (1991a). Sources of change in energy use in the US economy, 1972-1982: a structural decomposition analysis, Resources and Energy, 13, pp.1-21.

ROSE, A. \& CHEN, C.Y. (1991b). Modeling the responsiveness of energy use to changing economic conditions, in: F. FESHARAKI \& J. DORIAN (eds), Energy Developments in the 1990s, pp.31-51.

ROSE, A. and CASLER, S., (1996). Input-output structural decomposition analysis: A critical appraisal, Economic Systems Research, 8, Issue.1, pp.33-62.

SANTHANAM, K.V. and PATIL, R.H. (1972). "A study of the production structure of the Indian economy: an international comparison", Econometrica, Vol.40, pp.159-176.

SHUJA, N., WAH, Y. and LAZIM, M.A. (2007). Identify the Key Sector of Malaysian Economy: an Input-Output Approach, Proceeding of the 9th Islamic Countries conference of statistical science, 12-14 Dec, Shah Alam, Malaysia, pp.1340-1354.

SIEGEL, P.; ALWANG, J. \& JOHNSON, T. (1996). Decomposing sources of regional growth with an input-output model: a framework for policy analysis, International Regional Science Review, Vol.17, pp.

SIMPSON, D. and TSUKUI, J. (1965). 'The fundamental structure of input-output tables, an international comparison", Review of Economics and Statistics, Vol.47, pp.434-446.

SKOLKA, J. (1977). Input-output anatomy of import elasticities, Empirical Economics, 2, pp.123-136.

SKOLKA, J. (1989). Input-output structural decomposition analysis for Austria, Journal of Policy Modeling, 11, pp.45-66.

SOHN, I. (1986). Reading in Input-Output Analysis: Theory and Applications, Oxford University Press, New York.

SONIS, M., HEWINGS, G. J. D. \& GUO, J. (1996). Sources of structural change in input-output systems: a field of influence approach. Economic Systems Research, 8, pp.15-32.

STERNER, T. (1985). Structural change and technology choice: energy use in Mexican manufacturing industry, 1970-81, Energy Economics, 9, pp.77-86.

SYRQUIN, M. (1976). Sources of industrial growth and change: an alternative measure. Paper presented to the European Meeting of the Econometric Society, Helsinki, Finland.

WOLFF, E. N. (1985). Industrial composition, inter-industry effects, and the US productivity slowdown, Review of Economics and Statistics, 67, pp.268-277. 
Table 1. Aggregation of sectors:

\begin{tabular}{|c|c|c|c|}
\hline \multirow[t]{2}{*}{ No. } & \multirow[t]{2}{*}{ Sectors Names } & \multicolumn{2}{|c|}{ Input-Output Tables } \\
\hline & & $1991 \& 2000$ & $1983 \& 1987$ \\
\hline 1 & Agriculture products other & $1,4,5$ & 1 \\
\hline 2 & Rubber primary products & 2 & 2 \\
\hline 3 & Oil palm primary products & 3 & 3 \\
\hline 4 & Livestock breeding, etc & 6 & 4 \\
\hline 5 & Forestry, logging product & 7 & 5 \\
\hline 6 & Fishing, etc & 8 & 6 \\
\hline 7 & Crude oil, Gas, Mining, Quarrying Product & $9,10,11$ & 7 \\
\hline 8 & Foods Production other & $12-15,17-21$ & $8-9,11-13$ \\
\hline 9 & Oils and Fats product & 16 & 10 \\
\hline 10 & Animal Feeds product & 22 & 14 \\
\hline 11 & Beverages \&Tobacco product & $23-24,25$ & $15-16$ \\
\hline 12 & Textile Products & $26,27,28$ & 17 \\
\hline 13 & Wearing Apparel & $29,30,31$ & 18 \\
\hline 14 & Wooden Products & 32,33 & 19 \\
\hline 15 & Furniture \& Fixtures & 34 & 20 \\
\hline 16 & Paper \& Printing Products & 35,36 & 21 \\
\hline 17 & Industrial Chemicals & 37 & 22 \\
\hline 18 & Paints, Lacquers \& Other Chemical Product & $38-41$ & $23-24$ \\
\hline 19 & Petroleum, Coal Product & 42 & 25 \\
\hline 20 & Processed Rubber \& Rubber Product & $43-44$ & $26-27$ \\
\hline 21 & Plastic Products & 45 & 28 \\
\hline 22 & China, Glass, Clay, cement \& Other Non-met Mineral Products & $46-49$ & $29-31$ \\
\hline 23 & Basic Metal \& Other Metal Product & $50-54$ & $32-33$ \\
\hline 24 & Non-Electricity and Electricity Machinery & $55-59$ & $34-35$ \\
\hline 25 & Motor Vehicle Manufacturing & 61 & 36 \\
\hline 26 & Other Transport Equipment & $60,62,63$ & 37 \\
\hline 27 & Other Manufacturing Products & $64-65$ & 38 \\
\hline 28 & Electricity \& Gas & 66 & 39 \\
\hline 29 & Water works and supply & 67 & 40 \\
\hline 30 & Building \& Construction & 68 & 41 \\
\hline 31 & Wholesale \&Retail Trade & 69 & 42 \\
\hline 32 & Hotel \& Restaurants & 70 & 43 \\
\hline 33 & Transport & 71 & 44 \\
\hline 34 & Communication & 72 & 45 \\
\hline 35 & Banks, Financial \& Insurance & $73-75$ & $46-47$ \\
\hline 36 & Real estate \& Ownership dwellings & $76-77$ & 48 \\
\hline 37 & Education & $79-80$ & 50,56 \\
\hline 38 & Health & $81-82$ & 51,57 \\
\hline 39 & Other Services & $78,83-94$ & $49,52-55,58-60$ \\
\hline
\end{tabular}

Source: Malaysian Input-Output Tables for 1983, 1987, 1991 and 2000. 
Table 2. Comparison of production Activity by absolute column Measure.

\begin{tabular}{|c|c|c|c|c|c|c|c|}
\hline \multirow[b]{2}{*}{ Sector } & \multicolumn{7}{|l|}{ Tables } \\
\hline & 1983-1987 & 1983-1991 & 1983-2000 & 1987-1991 & $1987-2000$ & 1991-2000 & Mean \\
\hline 1 & 0.375 & 0.576 & 0.726 & 0.389 & 0.624 & 0.796 & 0.581 \\
\hline 2 & 0.472 & 0.450 & $1.011 *$ & 0.362 & $0.924 *$ & $1.111^{*}$ & 0.722 \\
\hline 3 & 0.240 & 0.590 & 0.693 & 0.709 & 0.683 & $0.996^{*}$ & 0.652 \\
\hline 4 & 0.296 & 0.599 & 0.631 & 0.403 & 0.448 & 0.209 & 0.431 \\
\hline 5 & $1.037 *$ & $1.129 *$ & 0.618 & 0.293 & $1.255^{*}$ & $1.243^{*}$ & $0.929^{*}$ \\
\hline 6 & $1.023 *$ & $0.985^{*}$ & $1.285^{*}$ & $1.223 *$ & $1.484 *$ & $1.008^{*}$ & $1.168^{*}$ \\
\hline 7 & 0.633 & 0.771 & $0.856^{*}$ & 0.521 & 0.524 & 0.361 & 0.611 \\
\hline 8 & 0.117 & 0.198 & 0.684 & 0.190 & 0.717 & 0.597 & 0.417 \\
\hline 9 & 0.085 & 0.105 & 0.229 & 0.050 & 0.206 & 0.194 & 0.145 \\
\hline 10 & 0.288 & 0.420 & 0.802 & 0.375 & $0.908^{*}$ & 0.702 & 0.583 \\
\hline 11 & 0.523 & 0.578 & 0.621 & 0.479 & 0.406 & 0.428 & 0.506 \\
\hline 12 & 0.347 & 0.566 & 0.745 & 0.368 & 0.720 & 0.573 & 0.553 \\
\hline 13 & 0.391 & 0.439 & 0.505 & 0.144 & 0.529 & 0.602 & 0.435 \\
\hline 14 & 0.308 & 0.381 & 0.419 & 0.178 & 0.208 & 0.201 & 0.282 \\
\hline 15 & 0.319 & 0.560 & $0.986^{*}$ & 0.334 & $0.923 *$ & 0.758 & 0.647 \\
\hline 16 & 0.252 & 0.207 & 0.566 & 0.186 & 0.561 & 0.593 & 0.394 \\
\hline 17 & $1.040^{*}$ & $0.916^{*}$ & 0.677 & 0.463 & $1.048^{*}$ & $0.928^{*}$ & $0.845^{*}$ \\
\hline 18 & 0.270 & 0.295 & 0.652 & 0.250 & 0.736 & 0.723 & 0.488 \\
\hline 19 & 0.264 & 0.474 & 0.351 & 0.228 & 0.504 & 0.585 & 0.401 \\
\hline 20 & 0.165 & 0.378 & $0.957^{*}$ & 0.450 & $1.050 *$ & 0.739 & 0.623 \\
\hline 21 & 0.338 & 0.331 & 0.495 & 0.459 & 0.485 & 0.586 & 0.449 \\
\hline 22 & 0.248 & 0.346 & 0.420 & 0.231 & 0.515 & 0.422 & 0.364 \\
\hline 23 & 0.476 & 0.781 & $0.836^{*}$ & 0.372 & 0.532 & 0.392 & 0.565 \\
\hline 24 & 0.330 & 0.417 & 0.362 & 0.534 & 0.436 & 0.373 & 0.409 \\
\hline 25 & 0.505 & 0.438 & 0.758 & 0.442 & 0.646 & 0.432 & 0.537 \\
\hline 26 & $1.008^{*}$ & 0.738 & $0.901 *$ & $1.142 *$ & $1.231 *$ & 0.389 & $0.902 *$ \\
\hline 27 & 0.487 & 0.622 & 0.655 & 0.350 & 0.716 & 0.706 & 0.589 \\
\hline 28 & $1.290^{*}$ & 0.634 & $1.184^{*}$ & $1.004 *$ & $1.173^{*}$ & $0.895^{*}$ & $1.030^{*}$ \\
\hline 29 & 0.426 & $1.168^{*}$ & 0.739 & $1.013^{*}$ & 0.708 & $0.895^{*}$ & $0.825^{*}$ \\
\hline 30 & 0.256 & 0.271 & 0.406 & 0.331 & 0.331 & 0.237 & 0.305 \\
\hline 31 & 0.203 & 0.506 & 0.761 & 0.418 & 0.768 & 0.791 & 0.575 \\
\hline 32 & 0.133 & 0.402 & 0.440 & 0.362 & 0.432 & 0.438 & 0.368 \\
\hline 33 & 0.232 & 0.433 & 0.520 & 0.319 & 0.549 & 0.514 & 0.428 \\
\hline 34 & 0.521 & $0.830^{*}$ & $1.029^{*}$ & $0.969^{*}$ & $1.044 *$ & $0.922 *$ & $0.886^{*}$ \\
\hline 35 & 0.381 & 0.304 & 0.480 & 0.199 & 0.540 & 0.482 & 0.398 \\
\hline 36 & 0.190 & 0.420 & $1.617^{*}$ & 0.375 & $1.555^{*}$ & $1.444 *$ & $0.933^{*}$ \\
\hline 37 & 0.363 & 0.716 & 0.750 & 0.590 & 0.650 & 0.677 & 0.624 \\
\hline 38 & 0.345 & 0.379 & 0.503 & 0.316 & 0.459 & 0.519 & 0.420 \\
\hline 39 & 0.190 & 0.370 & 0.431 & 0.374 & 0.440 & 0.472 & 0.379 \\
\hline
\end{tabular}

- Value $\geq 0.8$.

Source: Malaysian Input-Output Tables for 1983, 1987, 1991 and 2000.

Sector Name: As shown in Table 2.

Table 3. Classification of Columns by Frequency Distribution of PTj.

\begin{tabular}{|l|l|l|l|l|l|l|}
\hline Range of Pj & $83-87$ & $83-91$ & $83-2000$ & $87-91$ & $87-2000$ & $91-2000$ \\
\hline \hline $0.000-0.499$ & 30 & 21 & 10 & 30 & 10 & 14 \\
\hline $0.500-0.799$ & 4 & 13 & 18 & 4 & 18 & 16 \\
\hline $0.800-0.999$ & 0 & 3 & 6 & 1 & 3 & 5 \\
\hline 1.000 and above & 5 & 2 & 5 & 4 & 8 & 4 \\
\hline Total & 39 & 39 & 39 & 39 & 39 & 39 \\
\hline
\end{tabular}

Source: Table 2. 
Table 4. Comparison of Production Structure by Intermediate Use Measure, 1983-2000.

\begin{tabular}{|c|c|c|c|c|c|c|}
\hline \multirow[b]{2}{*}{ Sector } & \multicolumn{6}{|c|}{ Tables } \\
\hline & 1983-1987 & 1983-1991 & 1983-2000 & 1987-1991 & 1987-2000 & 1991-2000 \\
\hline 1 & $0.956^{*}$ & $1.167 *$ & 1.504 & $1.169 *$ & 1.463 & 1.356 \\
\hline 2 & $0.883 *$ & 1.345 & 3.579 & 1.529 & 4.187 & 2.813 \\
\hline 3 & $1.085^{*}$ & $1.117^{*}$ & $1.189^{*}$ & $1.029^{*}$ & $1.096^{*}$ & $1.068^{*}$ \\
\hline 4 & $1.019^{*}$ & $1.040 *$ & 1.525 & $1.009 *$ & 1.430 & 1.326 \\
\hline 5 & 0.770 & 0.692 & 0.534 & $0.893 *$ & 0.689 & 0.763 \\
\hline 6 & 1.394 & 1.486 & $1.189^{*}$ & $1.088^{*}$ & $0.940^{*}$ & $0.884 *$ \\
\hline 7 & 0.778 & $1.035^{*}$ & 1.403 & $1.191 *$ & 1.738 & 1.705 \\
\hline 8 & $1.042 *$ & $1.085^{*}$ & $0.806^{*}$ & $1.069^{*}$ & $0.812^{*}$ & 0.774 \\
\hline 9 & $0.988^{*}$ & $0.989 *$ & $0.839 *$ & $1.001 *$ & $0.849^{*}$ & $0.854^{*}$ \\
\hline 10 & $1.003 *$ & $0.884^{*}$ & $0.915^{*}$ & $0.880^{*}$ & $0.907 *$ & $1.026^{*}$ \\
\hline 11 & 0.704 & $0.825^{*}$ & $1.132 *$ & 0.994* & $1.173^{*}$ & 1.211 \\
\hline 12 & 1.216 & 1.631 & 1.500 & 1.323 & 1.206 & $0.875^{*}$ \\
\hline 13 & $1.152 *$ & 2.134 & 1.934 & 1.336 & 0.725 & 0.560 \\
\hline 14 & $0.917^{*}$ & 1.780 & 2.184 & 1.948 & 2.150 & $1.188^{*}$ \\
\hline 15 & $0.961 *$ & 1.251 & 0.751 & 1.371 & $0.904 *$ & 0.461 \\
\hline 16 & $1.027 *$ & $0.902 *$ & $1.116^{*}$ & $0.893^{*}$ & $1.125^{*}$ & 1.216 \\
\hline 17 & $1.022 *$ & 1.256 & $0.907 *$ & $1.176^{*}$ & $0.810^{*}$ & 0.736 \\
\hline 18 & 1.410 & 1.400 & $0.974 *$ & $0.980^{*}$ & 0.632 & 0.650 \\
\hline 19 & 2.357 & 1.800 & $0.957 *$ & $0.809 *$ & 0.427 & 0.575 \\
\hline 20 & $0.902 *$ & $1.008^{*}$ & $0.865^{*}$ & $1.182^{*}$ & $0.914 *$ & 0.747 \\
\hline 21 & $0.835^{*}$ & $0.900 *$ & 1.776 & $1.022 *$ & 1.811 & 1.655 \\
\hline 22 & $0.813^{*}$ & $0.836^{*}$ & 0.726 & $1.041 *$ & $0.898^{*}$ & $0.872 *$ \\
\hline 23 & $0.869^{*}$ & $0.883^{*}$ & 0.964* & $0.991 *$ & $0.958^{*}$ & $1.070^{*}$ \\
\hline 24 & 1.265 & 0.486 & 0.646 & 0.353 & 0.435 & 1.333 \\
\hline 25 & $1.196^{*}$ & 0.702 & 0.675 & 0.598 & 0.583 & $1.106^{*}$ \\
\hline 26 & 0.538 & 0.265 & 0.400 & 0.343 & 0.568 & 1.506 \\
\hline 27 & 1.272 & 0.535 & 0.530 & 0.407 & 0.392 & $0.875^{*}$ \\
\hline 28 & $1.011 *$ & 1.279 & $1.037 *$ & 1.249 & $0.966^{*}$ & 0.729 \\
\hline 29 & $1.043^{*}$ & $0.804^{*}$ & $0.844^{*}$ & 0.779 & $0.837^{*}$ & $0.983^{*}$ \\
\hline 30 & $1.126^{*}$ & $1.067 *$ & 1.839 & $0.962 *$ & 1.614 & 1.776 \\
\hline 31 & $0.980^{*}$ & $0.856^{*}$ & $1.037^{*}$ & $0.914^{*}$ & $1.029^{*}$ & $1.197 *$ \\
\hline 32 & $0.975^{*}$ & $1.166^{*}$ & $0.917 *$ & $1.189^{*}$ & $0.923 *$ & $0.808^{*}$ \\
\hline 33 & $1.093 *$ & $1.114^{*}$ & 1.308 & $1.034 *$ & 1.244 & $1.169^{*}$ \\
\hline 34 & 0.772 & 0.787 & 0.680 & $1.008^{*}$ & $0.836^{*}$ & $0.962 *$ \\
\hline 35 & $1.013^{*}$ & $1.059^{*}$ & 1.607 & $1.035^{*}$ & 1.633 & 1.608 \\
\hline 36 & $0.825^{*}$ & 0.693 & $0.835^{*}$ & $0.828^{*}$ & $1.009^{*}$ & $1.157^{*}$ \\
\hline 37 & 0.511 & 0.249 & 0.750 & 0.499 & 1.928 & 3.689 \\
\hline 38 & 0.608 & 0.730 & 1.367 & $1.144 *$ & 2.125 & 1.951 \\
\hline 39 & $1.062 *$ & $1.055^{*}$ & 1.356 & $0.976^{*}$ & 1.242 & 1.255 \\
\hline $\mathrm{R}(0.8-1.2)^{*}$ & 26 & 20 & 17 & 27 & 18 & 16 \\
\hline
\end{tabular}

* Value in critical range (0.8-1.2)

Source: Malaysian Input-Output Tables for 1983, 1987, 1991 and 2000 Sector Name: As shown in Table 1.

Table 5. Overall Comparison.

\begin{tabular}{|l|l|l|l|l|}
\hline Input-Output Table & $\mathbf{1 9 8 3}$ & $\mathbf{1 9 8 7}$ & $\mathbf{1 9 9 1}$ & $\mathbf{2 0 0 0}$ \\
\hline \hline 1983 & - & 1.002 & 0.980 & 1.040 \\
\hline 1987 & 1.006 & - & 0.969 & 0.999 \\
\hline 1991 & 1.026 & 1.026 & - & 1.095 \\
\hline 2000 & 0.981 & 0.984 & 0.958 & - \\
\hline
\end{tabular}

Source: Malaysian Input-Output Tables for 1983, 1987, 1991 and 2000.

Table 6. Overall Comparison with Mixed Combinations.

\begin{tabular}{|c|c|c|c|c|}
\hline \hline Input-Output Table & 1983 & 1987 & 1991 & 2000 \\
\hline \hline 1983 & 0 & 0.160 & 0.977 & 1.029 \\
\hline 1987 & & 0 & 0.972 & 1.007 \\
\hline 1991 & & & 0 & 1.069 \\
\hline 2000 & & & & 0 \\
\hline
\end{tabular}

Source: Malaysian Input-Output Tables for 1983, 1987, 1991 and 2000. 